\title{
O envelhecimento na perspectiva do cuidador de idosos
}

\author{
Aging by the perspective of elderly caregivers
}

Cléa Adas Saliba Garbin ${ }^{1}$

Doris Hissako Sumida ${ }^{1}$

Suzely Adas Saliba M oimaz ${ }^{1}$

Rosana Leal do Prado ${ }^{1}$

Milene M oreira da Silva ${ }^{1}$

${ }^{1}$ Programa de PósGraduação em Odontologia Preventiva eSocial, Núcleo de Pesquisa em Saúde Coletiva, Faculdade de Odontologia deAraçatuba, Universidade Estadual de São Paulo. Ruajosé Bonifácio 1.193, Vila M endonça. 16015-050 Araçatuba SP.

cgarbin@foa.unesp.br
Abstract This study reports elderly caregivers' perception in charge of giving assistance to three benefiting institutions in elderly care, in the city of Araçatuba, São Paulo, Brazil. Questions were approached regarding aging, caregivers' personal motivation in the search of working with this sector of population, relationship with elderly, most common difficulties found during work and caregivers' satisfaction. An interview was done with caregivers and the collected verbal material was analyzed through the Collective Subject Discursive Technique. It was possible to realize through the reports the emotional involvement of caregivers with their work as well as the emotional and physical overload which they are exposed to. Reports related to aging could also be collected as well as social questions which motivated caregivers to search for this kind of job. The several eyes of caregivers lead us to search for new strategies of theoretical capability and psychological support for this group, thinking of their wellbeing along with the elderly well-being. Key words Elderly, Aging, Caregivers
Resumo Este estudo relata a percepção de cuidadores de idosos que atuam em três institui ções de amparo ao idoso na cidadedeA raçatuba, São Paulo. Foram abordadas questões em relação ao enveIhecimento, motivações pessoais dos cuidadores em buscar trabalho com essa parcela da população, relacionamento com o idoso, dificuldades durante o trabalho ea sati sfação encontrada junto ao idoso. Realizou-se entrevista com os cuidadores, e 0 material verbal coletado foi analisado utilizando a técnica do Discurso do Sujeito Coletivo. Pôde-se perceber, através dos relatos, o envolvimento emocional do cuidador com seu trabalho, a sobrecarga física e emocional à qual está exposto. Relatos a respeito do envel hecimento também puderam ser coletados, além de questões de ordem social, que motivaram o cuidador a buscar esse tipo de trabaIho. Os diversos ol hares do cuidador nos impulsionam na busca deestratégias de capacitação teórica esuporte psicológico a essegrupo, pensando no seu bem-estar e no bem-estar do idoso.

Palavras-chave Idoso, Envelhecimento, Cuidadores 
Introdução

Com o avançar da idade surgem sensíveis alterações no estilo de vida da população idosa, por problemas de saúde ou mesmo pelo processo fisiológico do envelhecimento, que se configura como um processo múltiplo e desigual de comprometimento e decadência das funções que caracterizam o organismo vivo em razão do tempo de vida ${ }^{1}$.

0 aumento da expectativa de vida e a diminuição da taxa de mortalidade representam um fenômeno mundial atualmente, acarretando o envelhecimento populacional etrazendo profundas consequências para as políticas sociais, re presentando um dos maiores desafios da saúde pública contemporânea2,3.

No Brasil esse quadro não é diferente, e hoje o país já conta com mais de 14,5 milhões deido$\mathrm{sos}^{4}$. N essa perspectiva, estimativas indicam-no como sexto colocado em termos de população idosa no ano de2025, com mais de 30 milhões de habitantes acima de sessenta anos ${ }^{1,5}$.

As mudanças advindas da terceira idade le vam os idosos, em muitos casos, a necessitar de alguém para auxiliá-los em atividades que antes pareciam de simples execução. Dessa necessidade surge a figura de cuidador de idosos, que em muitos casos passa-nos sob um olhar desatento e sem a devida capacitação, resultando em desgaste tanto para 0 ser cuidado quanto para 0 cuidador. Entretanto, hoje no país, pouco se conhece do impacto, sobre o sistema de saúde, de idosos que estão dependentes enecessitam deum cuidador.

No Brasil, o cuidador não tem seu papel re conhecido, e tal lacuna é um fator a mais a ser considerado no planejamento de políticas públicas de saúde para idosos. Néri e Sommerhalder ${ }^{6}$ apontam a existência de uma incapacidade funcional como determinante da necessidade deum cuidador. Em países desenvolvidos, a figura do cuidador já é assimilada como parceira da equipe de saúde. $\mathrm{Na}$ Inglaterra, estima-se que mais de seis milhões de pessoas sejam cuidadores de indivíduos dependentes, em sua maioria idosos? ${ }^{7}$.

Sabe-seque essa parcela da população requer uma atenção especial em razão das condições sociais, mentais, físicas e afetivas nas quais vivem, em muitas das vezes situações detotal abandono social ${ }^{8}$. Portanto, pessoas que enveredam por essa área de atuação submetem-se, al gumas vezes, a condições extremas de desgaste não só físico como emocional. Por isso, é de grande importância uma boa formação técnica fundamen- tada não só em conceitos teóricos como também em aspectos humanos e éticos.

Pouco seconhecesobreo perfil decuidadores de idosos, suas necessidades, sua formação. A urgência deseestruturar uma equipemultidisciplinar qualificada com amplo conhecimento geriátrico e gerontológico é iminente, na busca da melhoria da qualidade de vida dos idosos institucionalizados.

Este estudo se propõe relatar a percepção dos cuidadores de idosos que atuam em três instituições de amparo ao idoso na cidade de Araçatuba, São Paulo, em relação ao envelhecimento, suas motivações pessoais em buscar trabal ho com essa parcela da população, seu relacionamento com o idoso, suas dificuldades durante o trabal ho ea satisfação encontrada junto ao idoso.

\section{M etodologia}

Foram entrevistados dezoito cuidadores, total existentenas instituições beneficiadas com o Projeto de Extensão Universitária promovido pelo Departamento de Odontologia Infantil e Social da Faculdade de O dontologia deA raçatuba (FOA) da Universidade Estadual de São Paulo (Unesp), intitulado Promoção deSaúdeem I dosos I nstitucionalizados da Cidade de Araçatuba/SP, que tem como objetivos a promoção, a prevenção e a recuperação da saúde bucal dos internos.

A entrevista foi gravada e teve tempo de duração aproximado de dez minutos, sendo obtido o termo de consentimento livre esclarecido dos participantes da pesquisa. Realizou-se um estudo piloto para validação e adequação do instrumento de coleta de dados. A modalidade da entrevista semiestruturada, ao mesmo tempo que valoriza a presença do investigador, oferece todas as perspectivas possíveis para que 0 informante alcance a liberdade e a espontaneidade necessárias, enriquecendo a investigação; mantém a presença conscientee atuante do pesquisador; e permite a relevância na si tuação do ator.

Para a análise do material verbal coletado em entrevistas gravadas, foi utilizada a técnica preconizada por Lefèvree Lefèvre9: Discurso do Sujeito Coletivo (DSC). Os autores esclarecem, em poucas palavras, que o DSC constitui uma técnica criada para fazer uma coletividade falar como se fosse um só indivíduo; como se o discurso de todos fosse o discurso de um. Ele oferece respostas ricas, detal hadas e altamente confiáveis. Por meio dele, pode-se compreender de forma mais viva e direta o modo como os indivíduos reais e 
concretos pensam. É uma expressão simbólica do campo, uma agregação de pedaços diferentes, de vários discursos individuais, que juntos irão compor uma referência coletiva?.

\section{Resultadosediscussão}

Ao analisar o relato gravado de todos os cuidadores, foram elaborados os discursos do sujeito coletivo de cada questão. Quando os profissionais (cuidadores) foram questionados sobre 0 significado de envelhecer, surgiram duas ideias centrais, indicando aspectos positivos e negativos do envelhecimento.

DSC

Eu costumo dizer que envelhecer é alguém na vida que tem muita experiência, sabedoria, échegar numa idade avançada com saúde, mesmo ve Ihinho fazendo tudo! É a realização dealguma coisa que você planejou, de bebê passa para criança, de criança pra adolescente, de adolescente para maior idadee daí, envelhecimento. É chegar numa idadefeliz.

DSC

Gostaria de não envelhecer, vai perdendo as forças, enfraquecendo. É um processo que não tem como evitar, da vida, que indica que o tempo chegou e nem sempre tem o amparo dos familiares. É difícil, humilhante, muito triste.

O primeiro tema explorado no DSC coincide com a opinião de Brunetti e $\mathrm{M}$ ontenegro ${ }^{10}$, acreditando queo idoso ainda podeser útil à sociedade com a experiência que acumulou durante a vida.

É possível ter saúdena terceira idade, com isso pode-se desfrutar do que a vida ainda proporciona, respeitando os limites do corpo, claro, porém não excluindo a chance de fazer o que lhe dá prazer. Borini e Cintra ${ }^{11}$ ressalvam que participar das atividades de lazer em grupos de terceira idade representa a saída do fundo do poço, traz um sentido para a vida e o próprio renascimento. Então, usufruir de todos os avanços médico-tecnológicos e mesmo da própria mudança de conceitos da sociedade é uma forma de envelhecer com saúde, alegria e bem-estar, excluindo a imagem ester eotipada de que com 0 envelhecimento 0 idoso fica acamado, à margem da sociedade.

Hazell et al. ${ }^{12}$ afirmam que exercícios físicos deresistência para adultos demaior idade, acompanhados de um profissional, são efetivos no aumento da força muscular, o que melhora a atuação dosidosos nas atividades diárias de vida. Isto quer dizer que se o idoso faz algum tipo de exercício físico diário, de preferência orientado por um profissional, elenão vai enfraquecer, pelo contrário: vai manter-se forte o suficiente para realizar suas atividades rotineiras e até outras, como a dança, por exemplo, o quelheproporciona saúde e bem-estar e, consequentemente, meIhoria na autoestima.

É certo que sexo, escolaridade, renda, proximidade com amigos e vizinhos, solidão, qualidade efetiva em relação à família, atividades de lazer, alimentação, cuidado corporal, deambulação, motilidade, estado mental, humor, acuidade visual, atividades domiciliares e extradomiciliares são variáveis que se mostram associadas à dependência dos idosos nos aspectos psicossociais eeconômicos, aspectos emocionais eatividade de lazer easpectos fisiopatológicos, como encontrado por Leite ${ }^{13}$. 0 aspecto psicológico deve ser muito bem trabal hado com o idoso, pois muitas vezes existem, de fato, 0 abandono da família e a solidão, o que pode acarretam um estado depressivo. Segundo I rigaray eSchneider ${ }^{14}$, a depressão é um dos problemas psiquiátricos mais comuns e importantes em idosos e caracteriza-se como um distúrbio da área afetiva ou do humor, que exerce forte impacto funcional em qual quer faixa etária. É de natureza multifatorial, que envolve numerosos aspectos de ordem biológica, psicológica e social, evivenciada muitas vezes como tristeza, saudade, angústia e desânimo. No entanto, não énecessariamente uma morbidade integrante da vel hice.

De nada adianta a família internar o idoso na melhor instituição de terceira idade se a saúde mental do ancião não épreservada. A saúde mental interfere muito na saúde geral, ao passo que, por mais que 0 idoso apresente todas as condições de ter uma vida saudável e segura, se ele não tem carinho, diversão, emoção ealegria, não tem ânimo para desfrutar de nada. Essa é a situação que os cuidadores de idosos deste estudo observam de perto a cada dia de serviço. Eles têm a percepção de que a tristeza, a solidão e o abandono não permitem que dias ensolarados sejam bem aproveitados, que as flores do jardim tenham beleza e que o palhaço do circo tenha sua graça para o idoso esquecido, principalmente porque é dessa forma "triste e humilhante" que esses profissionais consideram o envelhecimento. A falta de ânimo leva o idoso a se abandonar, atéo ponto de recusar a higiene do próprio corpo.

$M$ as existem tratamentos assistidos por profissionais que podem ajudar a envelhecer sem se ficar deprimido. De acordo com M oraes et al. ${ }^{15}$, a prática de exercícios físicos por indivíduosido- 
sos depressivos sem comorbidades é capaz de promover a prevenção e a redução dos sintomas depressivos. O u seja: a tristeza, a depressão, a solidão e a falta de exercícios físicos são fatores dependentes da força de vontade de cada indivíduo. Porém, em casos de pensamentos pejorativos, o idoso pode ser assistido por profissionais, tais como psicólogo, psiquiatra, fisioterapeuta, personal trainer, cirurgi ão- dentista, entre outros, para reverter o quadro e envelhecer com bemestar e qualidade de vida.

Um passeio matinal ou uma atividade artesanal acompanhados de pessoas queridas, brincadeiras com crianças e animais de estimação podem elevar o ponteiro da felicidade e isso garante a satisfação e o ânimo em viver, isto é: assim que se observa um comportamento pejorativo no ancião, deve-se estimulá-lo a realizar atividades quelhe proporcionem prazer e al egria, e esse estímulo funciona melhor quando é dado por alguém por quem o idoso tenha muita estima. Alguns dos cuidadores entrevistados tentam preencher esse vazio, em um curto e raro tempo de folga durante o serviço. Em al gumas das instituições-alvo desta pesquisa, foi possível observar que as atividades de lazer são mais frequentes e mais intensas; em outras, a visita de pessoas do terceiro setor (voluntariado), bem como o empenho delas em praticar artesanato e lazer com os internos, é o que mais Ihes proporciona o bem-estar.

Em 2004, Gazalle et al. ${ }^{16}$ já alertavam que a depressão nos idosos era pouco investigada em ambientes clínicos e sugeriam que os médicos ficassem mais atentos aos sinais da doença e rece bessem treinamento adequado no monitoramento de depressão nesse grupo etário. M as além da depressão, as alterações fisiológicas, psicológicas, sociais e até as alterações de memória podem ser observadas diariamente no cuidado do idoso. Assim, é importante que o cuidador de idoso te nha principalmentehabilidade esatisfação em trabal har com o ancião, pois caso contrário não tem sensibilidade suficiente para enxergar e compre ender tal situação, tampouco de observar a ne cessidade de cuidados específicos ou indicar profissionais especializados. Não ter noção do queé envelhecer é vendar os ol hos para si no futuro.

Talvez seja por essa suposta falta de interesse pessoal que, ao serem questionados sobre as maiores dificuldades do envel hecimento, os cuidadores tenham enfatizado as dificuldades físicas, psicológicas e aquelas encontradas durante o cuidado com o idoso.
DSC

As dificuldades que eu vejo estão aí na frente: maus- tratos, desrespeito em diversas áreas, familiares quenão aceitam um idoso dentro de casa dando um pouco mais detrabal ho, dependentedetudo, não enxergando direito, sem forças para andar sozinho, é debilitado. 0 velho enfrenta a solidão, 0 preconceito, as doenças. Quando tem Alzheimer sofre menos porque perde a noção de tudo o que está acontecendo. Quando é lúcido é pior porque entende tudo, tem queficar no asilo, tem medo das pessoas. Para cuidar de idosos acamados ou em cadeiras de rodas é preciso paciência.

Todas as mudanças consequentes do próprio envelhecimento acarretam desgaste tanto para 0 idoso quanto para o cuidador, do qual são requeridos paciência, habilidade e conhecimento para lidar com a situação. U ma vez que qual quer desses itens não esteja presente, muito facilmente haverá convergência da situação para o caminho que tange os maus-tratos.

Os maus-tratos contra idosos, descritos pela primeira vez em 1975, na Inglaterra, têm sido tema explorado em pesquisas científicasealvo deações governamentais em todo o mundo e no Brasil, vigorosamente, desde a última década ${ }^{17}$. Eles podem ser definidos como atos únicos ou repetidos - ou ainda ausência de ação apropriada que cause dano, sofrimento ou angústia - eque ocorram dentro de um relacionamento de confiança ${ }^{18}$.

$\mathrm{Na}$ literatura especializada, os maus-tratos são usualmente classificados em: físico, verbal, psicológico ou emocional, sexual, econômico, negligência e autonegligência ${ }^{18-20}$, levando para longe a ideia de que se trata apenas da agressão física.

Os violentados sentem a agressão desde um simples xingamento até espancamento, enquanto quem agride nem sempre se conscientiza de que aquele ato já é um ato de violência, como deixar detrocar a fralda urinada ou simplesmente deixar de dar um copo de água ao idoso. Os cuidadores entrevistados entendem o que é violência contra idoso; mas será que eles não a cometem de al guma forma? O cupar o cargo decuidador em uma instituição de terceira idade por falta de opção (e não por afinidade) e não dar atenção e carinho ao interno mais carente já sugereviolência.

A questão é que independentemente da forma de violência os idosos não costumam denunciar, por não conseguirem se locomover, por não terem contato com outras pessoas, por medo de maior agressão ou mesmo de abandono; e mesmo quando fazem a denúncia, ninguém acredita 
em seus relatos, pois eles não são considerados lúcidoso suficientepara dizerem verdades, esimplesmente são ignorados. Diante disso, exalta-se a importância da responsabilidade dos profissionais de saúde em detectar sinais de violência, orientar seus pacientes quantos aos tipos de apoio que eles podem recorrer e, principalmente, notificar a vigilância epidemiológica. Fernandes e Assis $\mathrm{s}^{21}$ explicam que certos tipos de lesões e ferimentos frequentes no idoso, sua aparência descuidada, desnutrição, comportamento muito agressivo ou apático, afastamento, isolamento, tristeza ou abatimento profundo são sinais que merecem investigação.

Quando se enfoca saúde global, as diferentes formas de violência contra o idoso comprometem sua qualidade de vida, acarretando somatizações, transtornos psiquiátricos e morte prematura, apontando que idosos vitimados por maus-tratos apresentam também uma taxa de mortalidade muito mais alta que a dos idosos que não sofreram abuso ${ }^{17}$.

Outro fator relacionado a essa situação é 0 nível de estresse do cuidador, que também é significante fator de risco para maus- tratos contra idosos ${ }^{22}$. Embora ainda se acredite que seja um fator contribuinte para a ocorrência de abuso, elenão responde, por si só, pela sua ocorrência ${ }^{17}$.

$M$ as se trabalhar com idosos causa tanto desgaste para quem presta este serviço, porque optar por ele? Os cuidadores explicaram que seria pelo interesseno emprego ou no salário, por ocupar a vaga por acaso, ou então por gostar.

DSC

Vim trabalhar aqui por necessidade, não foi opção de trabalho, precisava complementar minha renda, estava desempregada. Estava precisando de funcionário e eu fiquei sabendo da vaga e trouxe meu currículo aqui. Vim por acaso, não porque eu tinha vontade de trabalhar com idosos, eu achava que era uma coisa ruim, aí me interessei em fazer isso e depois eu gostei, preferi ficar aqui com eles, depois me apeguei. É muita satisfação em cuidar deles, me identifico muito. Tinha uma vontade muito grande de trabalhar com idosos etrabal har aqui, meu D eus, não tem comparação. Gosto muito de cuidar dos velhinhos.

Deacordo com o Instituto Brasileiro de Geografia e Estatística (IBGE) ${ }^{23}$, em 2002 a média da taxa de desemprego aberto situou-se em 7,3\%, 0 que é superior à média do período de janeiro a outubro de 2001 (6,3\%). Dados como estes podem ser colhidos em qualquer jornal ou telejornal diário brasileiro; no entanto, mesmo com a política atual estável, não se consegue erradicar o desemprego, levando o cidadão a trabalhar no emprego disponível no momento, não necessariamente na sua área de formação.

A função do cuidador de idoso, seja um profissional qualificado, seja um simples voluntário que nunca teve qualquer tipo de formação, éum "cargo" que demanda muita disposição, paciência, atenção e capacidade de entendimento por parte de quem presta o serviço. A capacitação, o conhecimento e o treinamento são importantes no trabalho do cuidador. Saliba et al. ${ }^{24}$ destacam que as mudanças ocorridas na terceira idade levam o ancião, em muitos casos, a necessitar de alguém para auxiliá-lo, e quando não é fornecida capacitação ao profissional, resulta um desgaste tanto para o ser cuidado quanto para 0 cuidador. Esses autores ainda enfatizam que quem cuida trabal ha pelos interesses de al guém e preocupa-se com esse alguém.

Os cuidadores entrevistados confirmaram estar no cargo por ser o único emprego que conseguiram. Considerando todos os pontos discutidos até agora, fica a dúvida se eles realmente estão preparados em prover o cuidado ao idoso institucionalizado, pois habilidades e virtudes, como a paciência, não fazem parte da índole de todos os seres humanos. Dessa forma, sugere-se que os internos estão mais vulneráveis aos maustratos, à falta de estímulo à manutenção da saúde mental eà falta decuidados específicos, quando o preenchimento do quadro de funcionários que lidam diretamente com o idoso (neste caso, os cuidadores) não exige seleção por qualificação e experiência profissional.

Quando as pessoas realizam atividades com as quais não têm afinidade ou habilidade, estas se tornam ocupações cansativas e estressantes, ficando muito aquém da excelência. $\mathrm{Caldas}^{25}$ ressalta que recebendo cuidado encontra-se um sujeito que tem uma dimensão existencial, sendo atingido pelos cuidados prestados pelo outro sujeito. Braun e $M$ arcus $^{26}$ alertam que os profissionais devem aprender uma novafilosofia quando forem tratar os pacientes idosos, mais do que um novo conjunto de habilidades clínicas etécnicas. Talvez uma seleção mais criteriosa pra tal cargo nas instituições possa contribuir para meIhoria na qualidade de vida dos internos emenor desgaste para quem presta o cuidado.

Brunetti e M ontenegro ${ }^{10}$ afirmam que todo profissional envolvido no cuidado eno tratamento do idoso deve ter como objetivo de sua atuação a manutenção da identidade do indivíduo ea criação de condições que lhe permitam envelhecer graciosamente. 
Dessa forma, o cuidador deve trabal har ofe recendo todo o benefício possível ao idoso. M as 0 ato de cuidar de alguém gera alguns conflitos até mesmo pela diferença de personalidades entre os seres, e por isso os cuidadores foram questionados sobre as dificuldades que eles tinham no cuidado com o idoso. Destacaram que as maiores dificuldades são dar atenção necessária, ter insegurança, não haver compreensão.

DSC

A dificuldade maior é atender eles na hora que eles querem. Eles começam a desabafar, contar que estão com saudade de alguém e eu não posso dar aquela atenção toda. Tem escassez de funcionário, tem que ter paciência com eles. Fico insegura na hora da alimentação, medo de engasgar, medo na hora do banho, de cair. Quando trabalho com os dependentes, não posso ajudar em algumas coisas como andar, enxergar... Quando eles ficam doentes, ficam muito frágeis. Saber a técnica é uma coisa, fazer funcionar é outra. A maior dificuldade étentar fazer eles entenderem o que eu quero fazer. $M$ uitas vezes eles não entendem.

É nítida a falta de cuidadores no quadro de funcionários das instituições, mas isso não justifica a falta de preparo dos entrevistados, principalmente quando se trata da insegurança no cuidado com o interno. A falta de compreensão desses cuidadores em relação à capacidade de entendimento de alguns internos pode levá-los a agir de forma rude e grosseira com o idoso. Eles entendem a fragilidade e a debilidade na saúde geral de alguns internos, masnão entendem quefornecer o cuidado ideal, dar carinho, amor e atenção são atitudes benéficas e confortantes ao ancião, uma forma de colaborar com o estado geral do idoso. Além disso, mesmo aqueles considerados "capacitados" por ter algum tipo deformação profissional, nem semprejá possuem experiência, poiseles mesmos relataram que é difícil colocar em prática todo o conhecimento (técnico) adquirido.

A falta de capacitação, de conhecimento e de prática do profissional que presta cuidados ao idoso gera insegurança, desorganização, irritação e falta de humanismo nele próprio. A maior vítima desse processo éo idoso que depende dos cuidados, pois não vai recebê-los adequadamente, o que prejudica seu bem-estar. A atenção aos simples gestos do ancião é fator que faz a diferença. Saber medicar e dar banho e alimentação nas horas certas não fazem da pessoa um profissional ideal para cuidar de idosos. É inegável a importância do conhecimento técnico, mas muito além do cateter existe um ser humano digno de respeito ecuidados especiais.
Esse respeito traz consigo a formação de elo entre as duas partes. Com isso, é possível que haja momentos bons durante todo o tempo de cuidados e atenção. Ao serem questionados sobre as satisfações que se adquiria ao cuidar de idosos, metade dos cuidadores não respondeu e a outra metade teve a mesma opinião: cuidar de idosos gera muita satisfação.

DSC

São muitas... eles me consideram e se apegam muito. Ficam alegres quando chego no serviço, não querem que eu vá embora, transmitem carinho, me proporcionam harmonia. É muito gratificante poder cuidar de uma pessoa e receber um sorriso, aprendo a valorizar as pessoas. Traz uma satisfação muito grande de estar valorizando a minha vida hoje, promove bem-estar e é muito gratificante.

Para quem já tem habilidade, gosto por cuidar de pessoas e tem afinidade com idosos, 0 papel do cuidador traz muita satisfação. Embora os cuidadores entrevistados sintam-se demãos atadas quando os anciãos possuem deficiências ou estão acamados, em outros momentos eles percebem que às vezes uma pequena atitude se torna imensa no entendimento do idoso. Desperta nesses cuidadores 0 afeto pelos internos, e a partir daí eles conseguem realizar 0 ato de cuidar com maior satisfação. 0 maior pagamento queo ancião pode oferecer a quem presta cuidados é o olhar de satisfação, suas histórias, experiência devida, consel hos e os gestos de gratidão.

Depois da criação do relacionamento entreo cuidador e a pessoa que está sendo cuidada, inicia-se muitas vezes um laço afetivo. A partir desselaço, a relação diária passa a ficar menos exaustiva e mais satisfatória, pois através da vivência surgem descobertas e realizações que fazem com que ambos os lados sintam-se bem. Segundo Cattani e Girardon-Perlini ${ }^{27}$, o cuidar apresentase como uma manifestação de afeto, uma concepção popular de amar, remetendo-nos a uma forma de compromisso com o outro. Os autores ainda exaltam que, nos casos de cuidadores que são filhos dos idosos, o ato de cuidar da própria mãe (ou do pai) transcende o ato em si, pois resgata o carinho, o amor, as desavenças do cotidiano e possibilita a retribuição de valores, de cuidados e também, de certa forma, o fato de existirem. Ao mesmo tempo, eles consideram as motivações que permeiam a tarefa de cuidar, e dessa forma observam queé evidenciada no cuidado uma forma de agradecimento pelas experiências vividas e pelos cuidados e atenção recebidos no passado. 
Para os cuidadores que conseguem obter satisfações e enxergam recompensas nesse serviço, o próprio processo de envelhecimento pode ser mais saudável e mais tranquilo porque el es compreendem tudo o que acontece com cada idoso; no entanto, para os outros, "envelhecer" ainda é muito difícil, humilhante, principalmente por haver dependência física efinanceira. Estes estão negligenciando a possibilidade de um dia se tornarem idosos e, pior, ignoram a hipótese de um dia compor o número de internos de um asilo, onde os profissionais não sejam qualificados, onde não haja ninguém para Ihes dar atenção e carinho, onde no meio de tanta gente seja possível sentir solidão. Não atentam para o fato de que um dia podem sentir-se bem e gratos por uma simples conversa com um cuidador mais atencioso emais paciente. Para estes, ainda épreciso crescimento, ou então viverão a prática do medíocre pensamento de que chegar à terceira idade é tornar-se velho.

\section{Conclusão}

A heterogeneidade expressa nas respostas dos cuidadores corrobora a diversidade da existência humana. 0 envolvimento emocional do cuidador com seu trabalho pôde ser observado de ângulos distintos: ao mesmo tempo que proporciona superação das deficiências técnicas, colabora também para a sobrecarga física e emocional de quem presta o cuidado, o que não nos deixa esquecer a importância da preservação da saúde (física, mental e emocional) do cuidador.
É necessário lembrar também que apenas o tratamento clínico do idoso na instituição não é suficiente para a qualidade de vida eo bem-estar, especialmente quando esse tratamento apresenta fal has no conhecimento técnico-científico, sendo necessária a prática de atividades físicas e de lazer, além do contato pessoal queinclui carinho, amor e atenção. Há ainda questões de ordem social que poderiam ser levantadas quando os cuidadores afirmam procurar esse trabalho por precisar de emprego, de renda. Diante desses fatos, é sugestivo que a instituição ofereça qualificação aos seus profissionais no que diz respeito a critérios técnicos e humanos, para que eles proporcionem aos idosos o melhor cuidado possível, resultando em uma vida intensa, longe da monotonia de uma instituição fechada, e possam também preservar sua saúde e bem-estar.

\section{Colaboradores}

CAS Garbin, DH Sumida, SAS M oimaz, RL Prado e M M Silva participaram, igualmente, da elaboração do artigo, sua discussão, redação e revisão. RL Prado eM M Silva participaram da coleta de dados realizada nas instituições asilares. 


\section{Referências}

1. Caldas CP. A saúde do idoso: a arte de cuidar. Rio de Janeiro: EdUerj; 1998.

2. Lima-Costa MF, Veras R. Saúde pública e envelhecimento. Cad Saude Publica 2003; 19:700-701.

3. Fried LP, Guralnik JM. Disability in older adults: evidence regarding significance, etiology and risk. J Am Geriatr Soc 1997; 45:92-100.

4. Brasil. Censo Populacional. Instituto Brasileiro de Geografia e Estatística [site na Internet]. [acessado 2007 out 10]. Disponível em: http://www.ibge.gov.br

5. Saliba CA, Saliba NA, M arcelino G, M oimaz SAS Auto-avaliação de saúde na terceira idade. RGO 1999; 47(3):127-130.

6. Néri AL, Sommerhalder $C$. As várias faces do cuidador e do bem-estar do cuidador. In: Néri AL, organizador. Cuidar de idosos no contexto da família: questões psicológicas e sociais. Campinas: Átomo \& Alínea; 2002. p. 9-63.

7. Grundy E. The epidemiology of aging. In: Tallis $R$, Fillit $H$, editors. Brocklehurst's textbook of geriatric medicine and gerontology. Edinburgh: Churchill Livingstone; 2003. p. 3-20.

8. Almeida MEL, Moimaz SAS, Garbin CAS, Saliba NA. Um olhar sobre o idoso: estamos preparados? Rev Fac Odonto (Porto Alegre) 2004; 45(1):64-68

9. Lefèvre $F$, Lefèvre $A M C$. Discurso do sujeito coletivo: um novo enfoque em pesquisa qualitativa (desdobramentos). Caxias do Sul: Educs; 2003.

10. Brunetti RF, Montenegro FLB. Odontogeriatria. São Paulo: Artes M édicas; 2002.

11. Borini M LO, Cintra FA. Representações sociais da participação em atividades de lazer em grupos de terceira idade. Revista Brasileira de Enfermagem 2002; 55(5):568-574

12. Hazell T, Kenno K, Jakobi J. Functional benefit of power training for older adults. J Aging Phys Act 2007; 15(3):349-359.

13. Leite RCBO. 0 idoso dependente em domićlio [dissertação]. Salvador: Escola de Enfermagem/Universidade Federal da Bahia; 1995.

14. Irigaray TQ, Schneider RH. Prevalência de depressão em idosas participantes da Universidade para a Terceira Idade. Revista de Psiquiatria do Rio Grande do Sul 2007; 29(1):19-27.

15. Moraes $H$, Deslandes A, Ferreira C, Pompeu FAM S Ribeiro P, Laks J. Exercício físico no tratamento da depressão em idosos: revisão sistemática. Revista de Psiquiatria do Rio Grande do Sul 2007; 29(1):70-79.

16. Gazalle FK, Hallal PC, Lima MS. Depressão na população idosa: os médicos estão investigando? Revista Brasileira de Psiquiatria 2004; 26(3):145-149.
17. World Health Organization. World report on violence and health. Geneva: World Health Organization; 2002. p. 123-145. [manual na Internet]. [acessado 2010 ago 13]. Disponível em: http://www.who.int/violence injury_prevention/violence/world_report/en/ summary en.pdf

18. Organização M undial da Saúde. M issing voices: views of older persons on elder abuse. Geneva: WHO/ INPEA; 2002

19. Pavlik VN, Hyman DJ, Festa NA, Dyer CB. Quantifying the problem of abuse and neglect in adults: analysis of a statewide database. Am J Geriatr Soc 2001; 49:45-48.

20. Rodríguez ME, Olivera A, Garrido G], García RR. $M$ altrato a los ancianos: estudio en el Consejo Popular de Belén, Habana Vieja. Rev Cubana Enferm 2002;18(3):144-153.

21. Fernandes M GM, Assis JF. M aus- tratos contra 0 idoso: definições e estratégias para identificar e cuidar. Gerontologia 1999; 7(3):144-149.

22. Cammer Paris BE. Violence against elderly people. Mt Sinai J Med. 1996; 63:97-100.

23. Instituto Brasileiro de Geografia e Estatística (IBGE). Pesquisa Mensal de Emprego [site na Internet]. [acessado 2007 nov 26]. Disponível em: http:// www1.ibge.gov.br/home/estatistica/indicadores/trabalhoerendimento/pme/pme102002crrs.shtm

24. Saliba NA, M oimaz SAS, Garbin CAS, M arques JAM, Prado RL. Perfil de cuidadores de idosos e percepção sobre saúde bucal. Interface - Comunic, Saúde, Educ 2007; 11(21):39-50.

25. Caldas CP. A dimensão existencial da pessoa idosa e seu cuidador. Textos Envelhecimento 2000; 3(4). [periódico na Internet]. [acessado 2007 out 12]. Disponível em: http://www.unati.uerj.br/tse/uerj

26. Braun RJ, M arcus M. Comparing treatment decisions for the elderly. Gerontology 1985; 1(4):138-142.

27. Cattani RB, Girardon-Perlini N M O. Cuidar do idoso doente no domicílio na voz de cuidadores familiares. Revista Eletrônica de Enfermagem 2004; 6(2). [periódico na Internet]. [acessado 2007 out 12]. Disponível em: http://www.revistas.ufg.br/index.php/fen

Artigo apresentado em 04/12/2007

Aprovado em 20/06/2008

Versão final apresentada em 06/08/2008 